Volume 11, Issue 12, December 2020, pp. 132-142. Article ID: IJM_11_12_015

Available online at http://iaeme.com/Home/issue/IJM?Volume $=11 \&$ Issue $=12$

Journal Impact Factor (2020): 10.1471 (Calculated by GISI) www.jifactor.com

ISSN Print: 0976-6502 and ISSN Online: 0976-6510

DOI: 10.34218/IJM.11.12.2020.015

\title{
GREEN MANUFACTURING: RETHINKING THE SUSTAINABILITY OF NIGERIAN MANUFACTURING FIRMS
}

\author{
MBANG Uduak. B. \\ Department of Management, Faculty of Business Administration, \\ University of Nigeria, Enugu Campus Nigeria \\ Dr. OGBO, A. I. \\ Department of Management, University of Nigeria, \\ Faculty of Business Administration, Enugu Campus Nigeria

\section{Dr. EMEH Ndidiamaka Chioma} \\ Department of Business Administration, Faculty of Management Science, \\ Enugu state University of Science and Technology, Nigeria
}

\author{
GABRIEL O. C. Okenwa
}

Apollos University, Great Falls, Montana, USA

\section{Dr. IHEONKHAN Iyere Samuel}

Department of Accounting, Faculty of Administration,

Nasarawa State University, Keffi, Nigeria

\section{Dr. AFOLABI Abiodun Ademola}

Department of Accounting, Faculty of Administration, Nasarawa State University, Keffi, Nigeria

\begin{abstract}
The global world continues to suffer the detrimental effect of water and air pollution on marine life and human health. The governments' desire to change the situation depends on their initiatives towards stemming the tide, and in recent years developing nations such as Nigeria have taken some initiatives to effect this change by promoting green manufacturing. This study used trend analysis to assess the impact of carbon emission, greenhouse gas, nitrogen oxide and methane emission emitted by firms on the ecosystem in Nigeria, and the value added by the manufacturing sector thereof. Data were sourced from the World Development Indicators and it was concluded that green manufacturing is a necessary practice to stem the tide and make the environment a living place for both animals and humans. It is recommended from
\end{abstract}


the findings that; there should be harmonized global environmental framework, which will serve as benchmark for global reporting on the effect of manufacturing activities on the ecosystem.

Key words: Ethics, sustainability, competitive advantage.

Cite this Article: MBANG Uduak. B., OGBO, A. I., EMEH Ndidiamaka Chioma, GABRIEL O. C. Okenwa, IHEONKHAN Iyere Samuel and AFOLABI Abiodun Ademola, Green Manufacturing: Rethinking the Sustainability of Nigerian Manufacturing Firms, International Journal of Management, 11(12), 2020, pp 132-142.

http://iaeme.com/Home/issue/IJM?Volume=11\&Issue=12

\section{INTRODUCTION}

Manufacturing is pivotal to the growth and development of the economy of any nation. As such, no economy can exist without the manufacturing sector. Consumer taste, needs and demand continue to increase both locally and internationally. This has led to efforts by the manufacturing firms to meet these demands via employing various strategies. The Nigerian Government have employed several strategies aimed at supporting the manufacturing sector ranging from import substitution industrialization strategy to the introduction of the Structural Adjustment Programme (SAP) in 1986 and other economic policies which all proved abortive [1].

The recognition of the relationship between manufacturing processes and the natural environment has become an important factor in the decision making among manufacturing firms.

Green manufacturing assumes that manufacturing firms evolve because of changes in the environment, and smart firms recognize the evolution of the industry and seek new opportunities because of these changes [2]. The aim of green manufacturing is to promote sustainability by ensuring that manufacturing activities enhance stakeholders' interests, as well as maximize economic, social values and environmental sustainability. Therefore, this study seeks to contribute to knowledge by examining the applicability of green manufacturing as a medium for rethinking the sustainability of Nigerian manufacturing firms with the aim of creating a roadmap for Nigerian manufacturing firms to transform their manufacturing activities in line with green manufacturing [3].

No other sector of the economy comes close to the manufacturing sector in generating vast volume of wastes. Manufacturing activities have given rise to increasingly severe environmental problems which have attracted substantial attention. As a consequence to offsetting these adverse environmental challenges, many manufacturing firms now face significant challenges in achieving growth while at the same time addressing the environmental problems that result from their production processes which over the long term, create a sinkhole which might swallow up the manufacturing sector, economy and the environment. To cope with this challenge, green manufacturing is considered to be an effective solution that can benefit both firms and their stakeholders. However, despite the need for green manufacturing as a criterion for global best practice, Nigerian manufacturing firms still lag behind and are missing out on the win-win opportunities that will enhance their competitiveness. It is against this background that this work seeks to analyse green manufacturing as a critical tool for rethinking the sustainability of Nigerian manufacturing firms.

The major objective of this work is to assess the applicability of green manufacturing as a rethinking tool for the sustainability of Nigerian manufacturing firms. The study used trend 
analysis to demonstrate the activities substance emission by manufacturing firms and manufacturing value added in Nigeria.

\section{HEADINGS}

The employment of technologies and manufacturing processes that minimize adverse environmental impacts conserve energy, and natural resources, while still maintaining the safety, reliability, and economic competitiveness, quality and quantity of products and services [4]. Green manufacturing aims at eliminating or curtailing wastes that negatively affect the environment. These wastes include toxic chemicals that are detrimental to the air, water, energy, solid wastes and stakeholders of the manufacturing firm. Green manufacturing is the renewal of production processes and the employment of environmentally friendly operations within the manufacturing field [5]. It is the greening of manufacturing, in which manufacturers reduce pollution and moderate emissions in their production processes. It involves not just the use of environmentally friendly raw materials, but also eco-friendly packing, distribution, and destruction or reuse after the lifetime of the product [6]. Green manufacturing seeks to harness natural energy flows and biological processes, eliminate reliance on fossil fuels and toxic materials, and improve resource efficiency [7].

\subsection{Industrial Emissions}

Industrial emissions are those gas pollutant emitted to the atmosphere during manufacturing activities. They can cause global warming and include [8];

Carbon emission: Carbon emission are toxic chemicals that are emitted into the atmosphere via combustion of fossil fuels (coal, natural gas, and oil), solid waste, trees and wood products, industrial activities and also as a result of certain chemical reactions.

Methane $\left(\mathrm{CH}_{4}\right)$ : Methane emissions also result from production activities, livestock and other agricultural practices and by the decay of organic waste in municipal solid waste landfills.

Nitrous oxide $\left(\mathrm{N}_{2} \mathrm{O}\right)$ : Nitrous oxide is emitted during agricultural and industrial activities, as well as during combustion of fossil fuels and solid waste.

Greenhouse gas: Fluorinated gases, Hydrofluoro carbons, perfluoro carbons, sulfur hexafluoride, and nitrogen trifluoride are synthetic, powerful greenhouse gases that are emitted from a variety of industrial processes. Fluorinated gases are sometimes used as substitutes for stratospheric ozone-depleting substances (chlorofluorocarbons, hydrochloro fluorocarbons, and halons).

The effect of each of these gases on the climate depends on how much of these gases are in the atmosphere, how long they stay in the atmosphere and how strongly they impact on the atmosphere [3].

\subsection{Recycling and Carbon dioxide $\left(\mathrm{CO}_{2}\right)$ Control}

Recycling is the practice of reusing items that would otherwise be discarded as waste [9]. It's almost inevitable that a certain amount of waste is generated in manufacturing processes. It is the enormous volume of scrap and rejected materials that manufacturing operations generate, and the balance that manufacturing firms must strike between rigorous production demands and equally rigorous safety and environmental standards. While this waste is often just dumped, green manufacturing entails that there are real opportunities for manufacturing firms to improve manufacturing efficiencies by recycling their waste [10]. Recycling and buying recycled goods helps reduce the amount of waste materials sent to landfills and incinerators, create jobs in the recycling and manufacturing industries, reduce energy needs for the manufacturing of many new products, conserve water and other natural resources and reduce 
pollution generated during the harvesting of raw materials [11]. As a manufacturer, it's crucial that recycling solutions is seamless and fully integrated with existing manufacturing operations [12]. This will add maximum value to the bottom line by cutting costs and increasing efficiency and at the same time curtail the Carbon dioxide (CO2) emitted into the environment.

WDE [13] reports that recycling in Washington continues to produce important environmental and economic benefits. While reducing the amount of waste going to landfills is important, recycling is more than a way to manage wastes it also reduces pollution and conserves natural resources. Using recycled materials to make new paper, plastic, glass, and metal products saves energy [12]. Collecting, processing, and transporting recycled materials almost always uses less energy. Less energy use also means few carbon dioxide (CO2) emissions.

\subsection{Choosing Green Materials and Methane $\left(\mathrm{CH}_{4}\right)$ Control}

Material selection has great importance in the design and development of products, it is as a philosophy gradually entering manufacturing industries for products to combat climate change [13]. The harvest and extraction of natural materials can cause substantial environmental harm, especially as supplies decrease and resource recovery becomes more invasive. Industrial materials often emit pollutants as by-product of their production process [14]. Choosing green material offers increased functionality and ease of use, longer life spans, easy disassembly or recyclability, and improved materials sourcing and production, which can all reduce the environmental impact associated with their production and use [13]. Gina [14] believes that all manufacturers can minimize environmentally related business risks by choosing materials that are; renewable, healthy and safe, non-toxic and are proven harmless over time.

Using environmentally friendly materials during manufacturing process is an excellent way for a company to become greener hence emission of Methane $\left(\mathrm{CH}_{4}\right)$ is curtailed. However, this approach is distinctly different from product to product, with some areas of manufacturing having more green options than others [15]. Manufacturing firms can source raw materials in an environmentally friendly fashion by getting them from waste streams, post-consumer waste, construction waste, or renewable agriculture sources [16]. When considering the ecological properties of materials, it is critical to go for materials that are abundant, non-toxic, have low embodied energy, and meet or exceed regulations. It is also critical to ensure that the material has the right physical properties to get the job done and that it won't drive up costs.

\subsection{Eco-innovation and Nitrous oxide $\left(\mathrm{N}_{2} \mathrm{O}\right)$ Management}

Eco-innovation refers to all forms of innovation technological and non-technological, new products, services and new business practices that results to the development of new business opportunities that benefits the environment by preventing or reducing their impact [17]. Ecoinnovation may as other innovations, be technical or organizational as long as they improve the green competitiveness of a company. It encompasses the entire innovation process from idea generation to manufacturing process to final product [18]. Eco-innovations are the products or services that improve the general environmental performance of customers. These innovations are environmental solutions that manage Nitrous oxide $\left(\mathrm{N}_{2} \mathrm{O}\right)$ emission. As such, eco-innovations help to reduce environmental burden or to reduce the costs of doing so. 


\section{INSTITUTIONAL THEORY}

This study is rooted in institutional theory. Institutional theory is traditionally concerned with how groups and organizations better secure their positions and legitimacy by conforming to the rules and norms of the institutional environment [18]. Based on the Institutional Theory external social, political, and economic pressures influence firms' strategies and organizational decisions as firms seek to adopt legitimate practices in the view of their stakeholders [19]. Institutional theory provides a theoretical lens through which manufacturing firms can adopt practices that promote the future of the sector, including factors such as culture, social environment, legal as well as economic environments. Institutional Theory describes three forms of drivers that promote sustainable manufacturing. These drivers are coercive, normative, and mimetic. Coercive occurs from influences applied by those in powerful positions, within and outside the firm (stakeholders). Coercive pressures are crucial to drive manufacturing firms towards sustainable manufacturing. Normative drivers ensure organizations conform in order to be perceived as partaking in legitimate actions. Once a set of organizations emerges as a field, a paradox arises: rational actors make their organizations increasingly similar as they try to change them. Normative pressures drive manufacturing firms to be more environmentally aware. This entails that the manufacturing sector engage in institutional research for better understanding on the new social rules (ethical values and ecological thinking) in order to respond accordingly. Normative drivers therefore exert influence because of a social obligation [20]. Mimetic drivers occur when manufacturing firms imitate the actions of successful competitors in the industry, in an attempt to replicate the path to success and legitimacy. Institutions create expectations that determine legitimate actions for manufacturing firms and also form the logic by which laws, rules, and taken-for-granted behaviour are assessed. Once Institutional philosophy becomes dominant, it affects the decision of firms by focusing the attention of executives towards the set of challenges and solutions that are consistent with the dominant philosophy and away from those challenges and solutions that are not. Therefore, institutions can define what is appropriate or legitimate and what acceptable behaviour is and thus render other actions unacceptable or even beyond consideration [18]. This will then affect how manufacturing firms make decisions. Thus, the Institutional theory perspective allows for focus on the role of conformity, regulatory and social pressures in driving Nigeria towards sustainable manufacturing.

Ahemad and Shrivastava [21] presented an empirical assessment and guides about measuring the past present and future state of art impact of green manufacturing (GM) in the Indian. To them Green manufacturing (GM) is fast emerging as the sustainable manufacturing solution that has the potential to solve most problems that the world faces today. GM covers the entire product life cycle from conceptual design to disposal in a benign, harmless manner causing no or minimal adverse impact on environment by optimum use of resources and reduction of waste and pollution. 4Rs (reduce, reuse, recycle, remanufacture) is slowly being accepted and adopted as the model of growth and sustainability the world over. There is a very large volume of literature available on GM dealing with several aspects. This paper in an attempt to comprehensively and systematically review the same and put it in a format which can be easily comprehended and applied by analysing around 123 papers from around 73 leading journals spread over last 15 years. This entire database is critically reviewed and properly classified by the authors. The analysis further revel several emerging issues and challenges which need to be addressed. The key challenge identified is the absence of unified comprehensive GM framework. The authors have finally suggested one such universal GM framework. 
Mao and Wang [22] examined empirical green manufacturing firms in China. Increasingly serious environmental problems, a circular economy production system is in urgent needs. This study explores whether green manufacturing (GM) is expensive and how external institutional environmental pressures influence the cost of GM among industrial enterprises in emerging economies. Through an analysis of 10,380 observations of 1470 listed manufacturing firms in the Chinese share market from 2008 to 2015, this paper finds that GM increases Operating Cost (OC). In addition, the positive relationship between GM and OC is strengthened with reduced pollution level in the local city. Furthermore, synergistic effects of the local pollution level and the local government's pollution information transparency are found. Firms' OC increases more as firms carry out GM when both the local pollution level and pollution information transparency of local government are high, or when the local pollution level and the local government's pollution information transparency are low.

Jayaraman, Singh, and Anandnarayan [23] examined the impact of sustainable manufacturing practices on consumer perception and revenue growth: an emerging economy perspective. The view that adopting an environmental perspective on manufacturing operations can lead to improved operations has become commonplace over the past decade. The implication is that any operational system that has minimized inefficiencies is also more environmentally sustainable. In the first phase of their research, they conducted a field research of the green manufacturing techniques in two phases; world-class, and ISO 14001certified paint manufacturing firms in India. This phase of the study was undertaken to ascertain the cost benefits that these firms enjoy due to green manufacturing and recycling. Based on the field work in these two companies, a conceptual framework was proposed to investigate any relationship between the consumer's attitude towards the environment and the perceived image of a company that was environmentally conscious. Subsequently, a survey was administered to understand the impact of green marketing on the decision of consumers to buy paint manufactured by a firm that stringently regulates its hazardous waste. Results indicate that there is a strong correlation between the environmental concern of the survey respondent and the perception that the respondent forms of the firm that has implemented green manufacturing techniques. There is also a strong correlation between the decision to buy a green product and the respondent's concern for the environment as well as the perception formed of the firm. Further research is required to substantiate the cost benefits of green manufacturing.

\section{METHODOLOGY AND DATA ANALYSIS}

The design adopted in this study was an ex post facto (after the fact) design. This is because the events had already taken place before the investigation is carried out. The choice of this design is made because the researcher has no control of the independent variables and inferences about the relationship among the variables are made without the current interaction among the regressed and the regressors [24]. The design is predicated on various econometric techniques such as Augmented Dickey-Fuller (ADF) and Philip-Peron (PP) unit root tests, granger causality test, threshold analytical technique and autoregressive distributive lag model also known as bound testing co-integration test, as well as the trend analysis of stylized facts on some of the indicators of variables of concern. The trend of carbon dioxide emission, greenhouse gas emission, nitrogen oxide and methane were used to analyze the impact of the substances on manufacturing value added in Nigeria.

The analysis contained the trend of substance emission on the environment. These substances are carbon emission, greenhouse gas emission, nitrogen oxide and methane. 


\subsection{The trend of carbon emission (CO2EM) in Nigeria}

The trend of carbon emission is as illustrated in figure 1. The intensity of emission in Nigeria is high with a capacity of 68154.86 kilograms in 1982 but plummeted on the average to 35199.53 and 37869.10 kilograms between 1995 and 1999. It trended upward to 106067.95 in 2006 but reduced to 98854.21 in 2017 , due to initiatives put in place to cushion the rate of effluent.

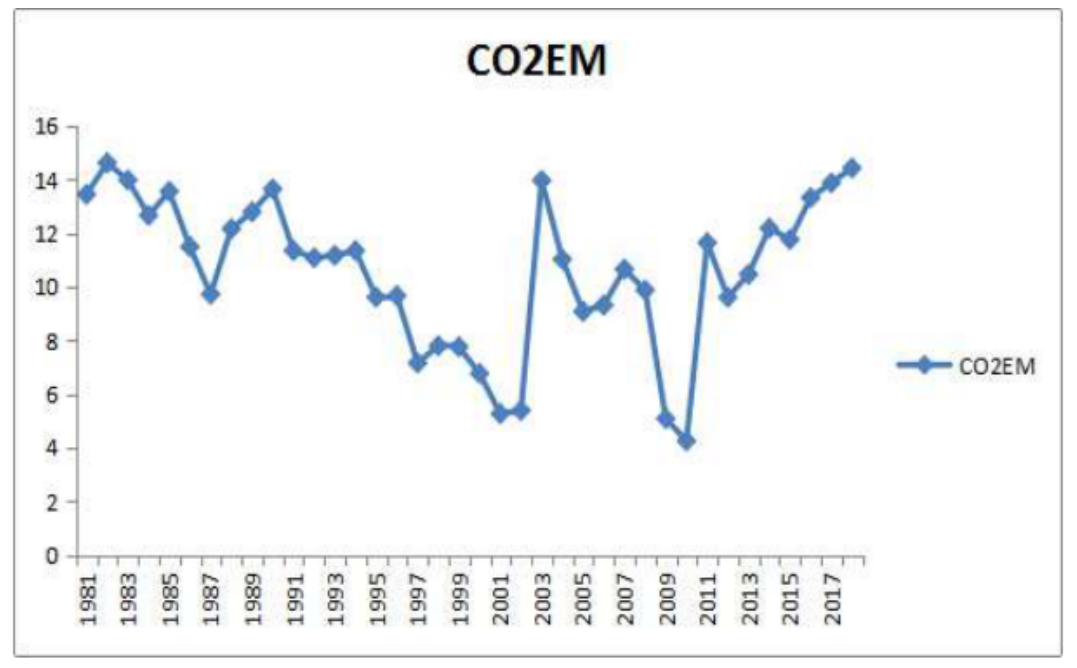

Figure 1 Carbon emission for Nigeria, 1981-2017

Source: World Development Indicators, 2018.

\subsection{The greenhouse gas}

The greenhouse gas emitted into the environment shows upward trend in Nigeria during the period under review. It rose phenomenally from 134625.32 metric tons in 1982 to all time high of 374421.70 metric tons in 2006. It maintains a steady increase between 1982 and 1998with 130472.48 metric tons of greenhouse gas flared into the environment as illustrated in figure 2. It was 147653.40 in 2017. The intensity of gas flared in Nigeria within the years under review.

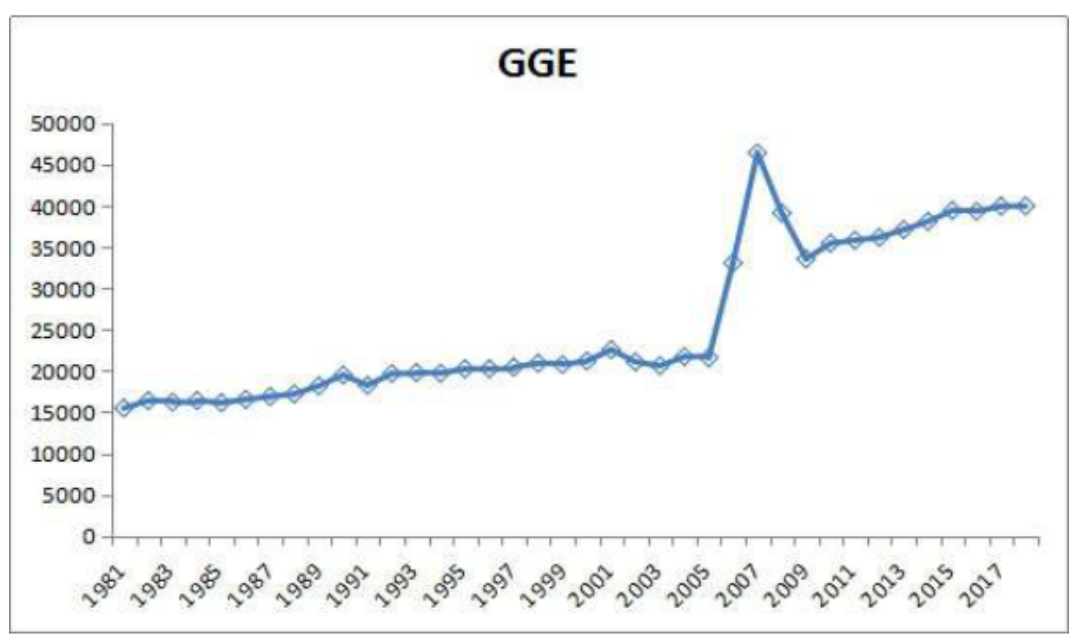

Figure 2 Greenhouse gas emission(GGE) for Nigeria, 1981-2017

Source: World Development Indicators, 2018. 


\subsection{Increase in the Rate of Nitrogen Oxide}

A phenomenal increase in the rate of nitrogen oxide was experienced in Nigeria between 1983 and 2006 with the average emitting capacity of 21569.30 tons. The intensity of the nitrogen emission in Nigeria was abysmally high in 2008 with 46431.49 metric tons, but plummeted to 39876.43 ton in 2017.

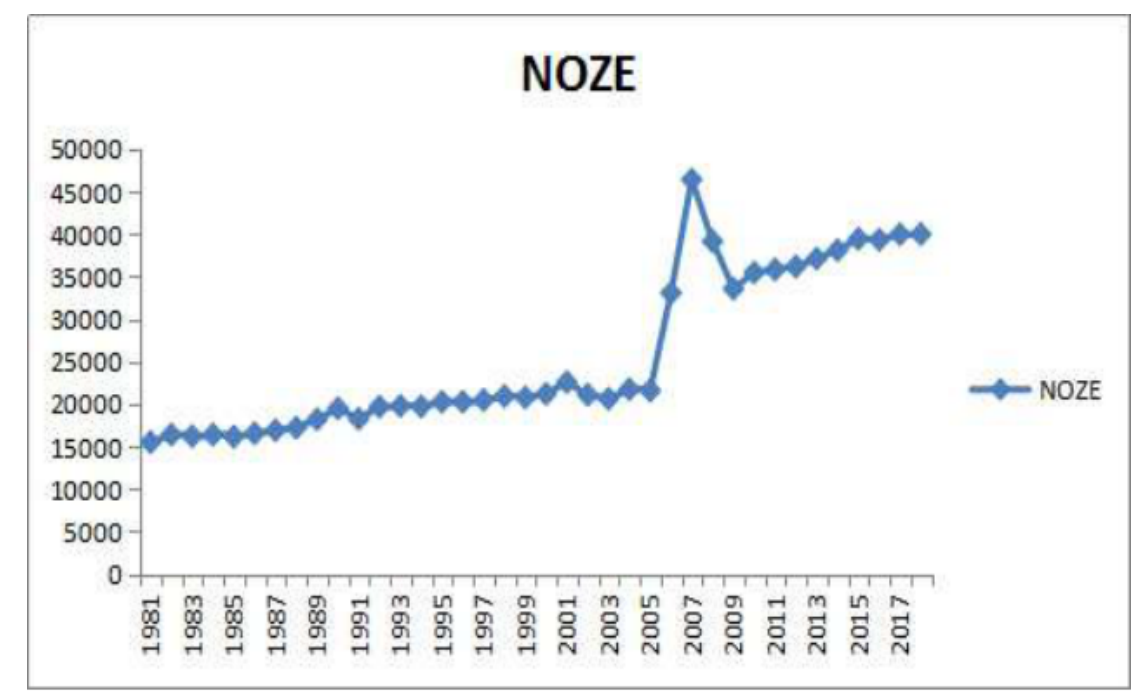

Figure 3 Nitrogen oxide emission (NOZE) for Nigeria, 1981-2017

Source: World Development Indicators, 2018.

\subsection{The intensity of methane emission}

The intensity of methane emission is mostly experience in Nigeria, with an average of 102391.00 in 2007. It trended marginally through 2015 but dropped to 73456.32 in 2017.

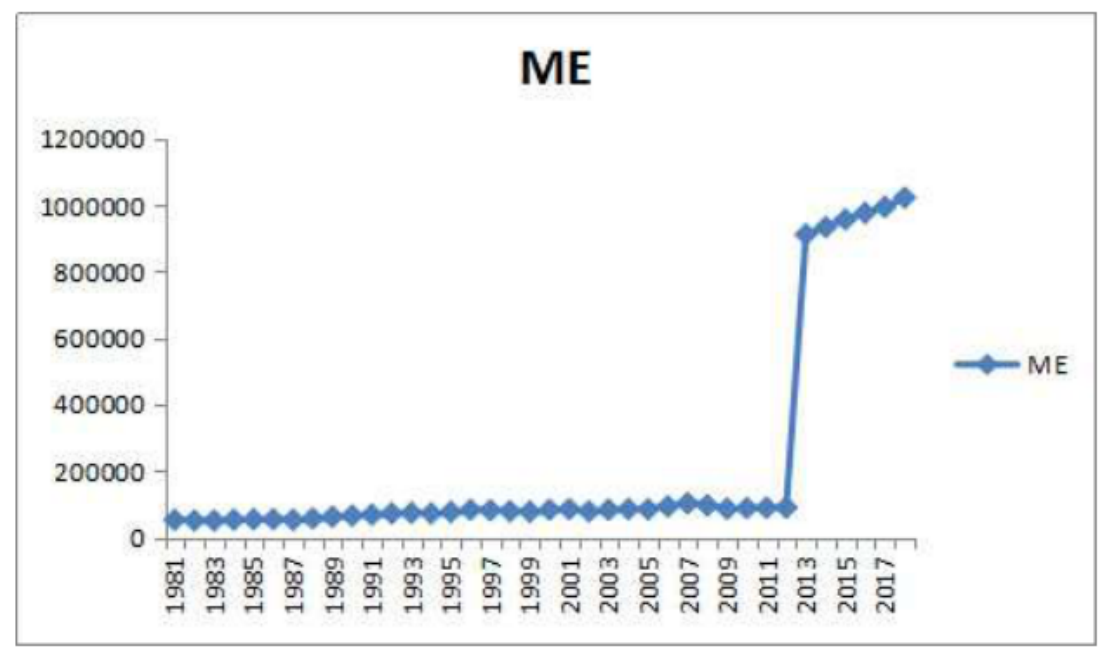

Figure 4 Methane emission (ME) for Nigeria, 1981-2017

Source: World Development Indicators, 2018.

The environmental effect of carbon emission, greenhouse gas emission, Nitrogen oxide and methane has been high as illustrated in the figures above. From the analysis, it can be observed that these substances have severe impact on the environment. Manufacturing firms have not been able to capture these effects on the ecosystem this pose a lot of challenges, mostly in Nigeria where the effect is severe. 
However, dangerous hydrocarbons are emitted into the air as a result of industrial activities. This is dangerous to man and other living organisms. The effects toxic chemicals emitted into the atmosphere in the course of burning fossil fuels, production activities, wastes discharge, amongst others via the activities of the manufacturing sector in Nigeria cannot be over-emphasized. Various effects of different hydrocarbons on health have been discussed in extant literature. These include methane like substances such as benzene which on chronic exposure may cause leukemia and birth defects, ethlybenzene which may cause dizziness, slower reflexes, loss of consciousness and death; zylene which may cause damages to a developing fetus, liver, kidney, skin, eyes, and bone marrow [25].

The search to meet customer taste and demands without having to compromise on the 4Ps (price, product place and promotion) have made manufacturing firms to be more profit conscious to the detriment of the environment. This have made the issue of sustainable development very difficult more so when man's continual exploitation of natural resources is without recourse to emerging stress and problems arising from such activities [26]. The manufacturing value added has been in abysmal performance over the years as shown in the trend, due to lack of green industrialization. It has a negative average value of 3.4 percent between 1981 and 1990. It further trended negatively with an average of 2.0 percent between 1991 and 2000, but became positive, averaging 2.1 percent between 2001 and 2010. It rose to 7.8 percent on the average between 2011 and 2018 (WDI, 2018).

\section{CONCLUSION}

The study assessed the trend of green manufacturing and the sustainability of Nigerian manufacturing firms. The global world continues to suffer the detrimental effect on marine life, agriculture and human health from water and air pollution caused by the activities of the manufacturing sector. The desire to change the situation depends on sustainable initiatives towards stemming the tide. Most developed countries have adopted the Green Manufacturing initiative and extant literature have shown that those who engage in this practice have measureable benefits for doing so; ranging from developed notable recognition for doing so to new lines of business. In recent years some developing nations including have taken some initiatives by controlling the activities of their manufacturing sector. The issues have been that of compliance and enforcement and of creating a safety-net mechanism that will allow both firms and their stakeholders (investors, customers, environmental organizations, host communities) a clear perspective on the total environmental effect of the sector.

It is recommended from the findings that; there should be harmonized global environmental initiative, which will serve as benchmark for global reporting on environment. The governments of Nigeria should step-up enlightenment programmes on policies and laws on environmental protection in order to increase awareness amongst corporations operating in the country. Also, the relevant agencies should ensure enforcement of and compliance with these policies and laws. The principles of environmental reporting such as sustainability, accountability and transparency should be constantly practiced in Nigeria. The severity of substance emission into the environment is high in Nigeria, hence Nigeria should improve on its environmental sustainability frame work through robust manufacturing control platform that will cushion the effect on the ecosystem.

\section{REFERENCES}

[1] O. J. Nnanna, S. O. Alade, F. O. Odoko, and Central Bank of Nigeria, Eds., Contemporary economic policy issues in Nigeria. Abuja: Central Bank of Nigeria, 2003.

[2] P. D. Jennings and P. A. Zandbergen, "Ecologically Sustainable Organizations: An Institutional Approach," The Academy of Management Review, vol. 20, (4), 1995, 15-52. 
[3] OECD, Towards Green Growth: Monitoring Progress: OECD Indicators. OECD, 2011.

[4] M. A. Rosen and H. A. Kishawy, "Sustainable Manufacturing and Design: Concepts, Practices and Needs," Sustainability, vol. 4, (2), 2012, 154-174.

[5] M. A. Rehman, D. Seth, and R. L. Shrivastava, "Impact of green manufacturing practices on organisational performance in Indian context: An empirical study," Journal of Cleaner Production, vol. C, (137), 2016, 427-448.

[6] A. I. Ogbo, N. C. J. Eneh, A. E. K, B. I. Chukwu, and D. O. Isijola, "Strategies for achieving sustainable economy in Nigeria taking into consideration the acceptable stakeholders," AJBM, vol. 11, (19), 2017, 582-589.

[7] T. Baines, S. Brown, O. Benedettini, and P. Ball, "Examining green production and its role within the competitive strategy of manufacturers," Journal of Industrial Engineering and Management, vol. 5, (1), 2012, 53-87...

[8] R. Kajaste and M. Hurme, "Cement Industry Greenhouse Gas Emissions - Management Options and Abatement Cost," Journal of Cleaner Production, vol. 112 (5), 2016, 41-52.

[9] F. Ackerman, Why Do We Recycle? Island Press, 1997.

[10] "Recycling Basics | Reduce, Reuse, Recycle | US EPA." 2020. Retrieved from; https://www.epa.gov/recycle/recycling-basics.

[11] D. Durant and A. Lucas, "Manufacturing a Better Planet: Challenges Arising from the Gap between the Best Intentions and Social Realities," Recycling, vol. 3, (2), 2018, 17-19.

[12] N. Malin and A. Wilson, "Material Selection: Tools, Resources, and Techniques for Choosing Green," Building Green, 1997. Retrieved from;

https://www.buildinggreen.com/feature/material-selection-tools.

[13] Washington Department of Ecology's (WDE). Recycling Survey: Savings are relative to energy required and GHGs emitted during production of products using virgin materials; EPA WaRM) 2013.

[14] B. Gina: Sustainability for manufacturers: driving profitability and growth. Autodesk, Inc., in the USA 2008.

[15] L. Anojkumar, M. Ilangkumaran and V.Sasirekha; Comparative analysis of MCDM methods for pipe material selection in sugar industry. Expert Systems with Applications, 41(6), 2014, $64-80$.

[16] O. Jamie: Green Materials Selection.

https://sustainabilityworkshop.autodesk.com/products/green-materials-selection. 2017.

[17] S. G. Azevedo, M. Brandenburg, H. Carvalho, and V. Cruz-Machado, Eds., Eco-Innovation and the Development of Business Models: Lessons from Experience and New Frontiers in Theory and Practice. Springer International Publishing, 2014.

[18] P. J. DiMaggio and W. W. Powell, "The Iron Cage Revisited: Institutional Isomorphism and Collective Rationality in Organizational Fields," American Sociological Review, vol. 48, (2), 1983, 147-160.

[19] P. Jennings, and P. Zandbergen. Ecological sustainable organisations: An institutional approach,Academy of Management Review, 1995.

[20] J. G. March: Exploration and Exploitation in Organizational Learning. Organization Science, 2, (1), 1991.

[21] M. Ahemad and R. Shrivastava, "Green manufacturing (GM): Past, present and future(a state of art review)," World Review of Science, vol. 10, pp. 17-55, 2013.

[22] Y. Mao and J. Wang, "Is green manufacturing expensive? Empirical evidence from China," International Journal of Production Research, vol. 57, (23) 2019, 35-47. 
MBANG Uduak. B., OGBO, A. I., EMEH Ndidiamaka Chioma, GABRIEL O. C. Okenwa, IHEONKHAN Iyere Samuel and AFOLABI Abiodun Ademola

[23] V. Jayaraman, R. Singh, and A. Anandnarayan, "Impact of sustainable manufacturing practices on consumer perception and revenue growth: an emerging economy perspective," International Journal of Production Research, vol. 50, no. 5, pp. 1395-1410, Mar. 2012.

[24] L. Cohen, L. Manion, K. Morrison, L. Manion, and K. Morrison, "Ex post facto research," Research Methods in Education, 2013.

[25] H. K. Mohajan, "Dangerous Effects of Methane Gas in Atmosphere," p. 12, 2012.

[26] N. O. Adeoye and B. Ayeni, "Assessment of deforestation, biodiversity loss and the associated factors: case study of Ijesa-Ekiti region of Southwestern Nigeria," GeoJournal, vol. 76, (3), 2011, 229-243. 